\title{
Cytotoxic Evaluation of Plant Essential Oils in Human Skin and Lung Cells ${ }^{1}$
}

\author{
Changhwan $\mathrm{Ahn}^{2} \cdot$ Mi-Jin Park ${ }^{3} \cdot \mathrm{Jae}$ Woo $\mathrm{Kim}^{3} \cdot$ Jiyoon Yang ${ }^{3} \cdot$ \\ Sung-Suk Lee ${ }^{3} \cdot$ Eui-Bae Jeung $\mathbb{( D}^{2, \dagger}$
}

\begin{abstract}
Plant essential oils are defined as fragrant volatile oils extracted from leaves, stems, fruits, flowers, and roots of a plant. Such oils are composed of multiple components and multiple functions. By accumulation of inductive information, various plant essential oils have been studied for using in therapeutic medicine for various diseases. Despite of the apparent advantages of essential oils as a source of therapeutic medicines, plant essential oils have many limitations, including cytotoxic side effects. Therefore, it is necessary to evaluate the toxicity and the mechanisms of cytotoxicity of such oils. In this study, we evaluated the cytotoxicity to human-derived cell lines of 10 plant essential oils provided by National Institute of Forest Science (i.e., Larix kaempferi; Abies holophylla; Zanthoxylum ailanthoides; Pinus parviflora; Tsuga sieboldti; Chamaecyparis pisifera; Cryptomeria japonica; Pinus densiflora; Illicium anisatum; Pinus thunbergii). Cytotoxicity evaluations were accomplished by using CCK-assays and PCR-based cytotoxicity-related marker gene analyses with A549 cell line, and the Detroit551 cell line which are lung and skin cell line. The genes were analyzed included caspase-3 has a role in cell apoptosis, and the other cyclinA, cyclinB, cyclinD, and cyclinE regulated cell cycling for the cell proliferation. By examining the five cytotoxicity-related marker genes by performing real-time PCR and examined the cytostatic gene regulation associated with the various essential oils. The results of this study showed that the degree of cytotoxicity and the cytostatic gene regulation which could give precious information for using the plant essential oil for the clinical usages.
\end{abstract}

Keywords: essential oil, cytostatic effect, cytotoxicity

\section{INTRODUCTION}

A plant essential oil is a volatile natural compound that is obtained as a secondary product of the plant and is characterized by a strong smell (Galindo et al., 2010). The components of a plant essential oil depend on the species of plant, and of the plant (Kahkonen et al., 1999; Lee et al., 2014). Oils may be extracted from different parts of the plant, such as leaves, fruit peels, seeds, bark, wood wicks, and flowers, and are usually obtained via steam or hydro-distillation (Waseem and Low, 2015). Over the centuries, plant

${ }^{1}$ Date Received January 9, 2018, Date Accepted March 12, 2018

${ }^{2}$ Laboratory of Veterinary Biochemistry and Molecular Biology, College of Veterinary Medicine, Chungbuk National University, Chungbuk 28644, Republic of Korea

${ }^{3}$ Division of wood chemistry \& Microbiology, Department of Forest Products, National Institute of Forest Science, Seoul 02455, Republic of Korea

$\dagger$ Corresponding author: Eui-Bae Jeung(e-mail: ebjeung@chungbuk.ac.kr, ORCID: 0000-0001-8936-916X) 
essential oils have been interested as sources of natural products (Prabuseenivasan et al., 2006). Plant essential oils have been widely used in the food and perfume industries until now due to their fragrance and flavor (Lee et al., 2017). Extracts having characteristics that can kill insects have been used as insecticides, while extracts having antibiotic and antifungal activity have been used as alternative treatments for diseases (Zhang et al. 2016). However, despite the great interest in the long-term usage of plant essential oils, science-based research into essential oils has been not revealed (Lambert et al., 2001; Sienkiewicz et al., 2014).

Cytotoxicity was determined by using CCK-assays and PCR-based cytotoxicity-related marker gene analyses. The genes analyzed included caspase- 3 , which has a role in cell apoptosis, and cyclinA, cyclinB, cyclinD, and cyclinE, which have roles in each stage of the cell cycle. Caspase-3 is a mammalian homolog of the ced-3 gene and has an essential role in the execution of cell apoptosis (Namura et al., 1998). In mammals, caspases (mainly caspase-3) are reported to be activated in the proteolytic cascade, leading to inadequate activation or rapid inactivation of key structural proteins, significant signal transduction, homeostasis, and repair enzymes (Porter and Janicke, 1999).

The cell cycle is divided into four stages; (Bravo and Celis, 1980) An S phase in which DNA is synthesized, an $\mathrm{M}$ phase in which mitosis occurs, and the G1 and G2 phase occur between S and G phases (Elledge, 1996). The signaling pathway regulating the progression of the cell cycle is known to be mainly related to the G1 phase (Grana and Reddy, 1995; Elledge, 1996). Cyclins are thought to be involved in interactions with upstream regulatory proteins, subcellular localization, timing of activation of Cdks, and substrate specificity and its catalytic subunit (Ohtsubo et al., 1995). CyclinA has a role in regulating the human cell cycle, and cyclinA kinase activity appears in the S and G2 phases (Pagano et al., 1992). A cyclinB complex with $\mathrm{Cdc} 2$ kinase has an essential role in providing the leading signal to trigger mitosis (Ha et al., 2005). The activity of cyclinB increases in the G2 phase and decreases after completion of cell division (Muschel et al., 1991). CyclinD is a key regulator that binds to Cdk4 and Cdk6 to form a holoenzyme and has an essential role in G1 phase progression (Sherr, 1994). CyclinE provides the function of the G1 phase in mammalian cells, and the cyclinE-Cdk2 complex exhibits maximum activity when moving from the G1 phase to the S phase (Wang et al., 2008). Overexpression of cyclinE reduces the time it takes for cells to terminate G1 and enter the S phase (Ohtsubo et al., 1995). So, cyclins are thought to be involved in interactions with upstream regulatory proteins, subcellular localization, timing of activation of Cdks, and substrate specificity and its catalytic subunit (Ohtsubo et al., 1995).

In this study, we suggest guidelines for the degree of toxic concentrations in Korean plant essential oils when we will apply in various fields. In this study, The essential oils evaluated for $\mathrm{IC}_{50}$ from larch (Larix kaempferi), fir (Abies holophylla), paulownia (Zanthoxylum ailanthoides), white pine (Pinus parviflora), tsuga (Tsuga sieboldti), cypress (Chamaecyparis pisifera), cedar (Cryptomeria japonica), red pine (Pinus densiflora), anise (Illicium anisatum), and black pine (Pinus thunbergii). We also determined the essential oil-induced cytostatic effect with four cell cycle markers (cyclinA, cyclinB, cyclinD, and cyclinE) and one cell death marker (caspase-3).

\section{MATERIALS and METHODS}

\subsection{Extraction of Plant Essential Oils}

Plant essential oils are extracted by hydrodistillation method. Add $1 \mathrm{~kg}$ of plant leafs and 10L of distilled water on heating mantle (MS-DM608, MTOPS ${ }^{\circledR}$, Republic of Korea) at $102^{\circ} \mathrm{C}$. Volatile steam is condensed in dean stark trap. Acquired essential oils are dehydration with sodium sulfite anhydrous, stored at $4^{\circ} \mathrm{C}$. 


\subsection{CCK Assay}

A549 and Detroit551 cells (Korean cell line bank, Republic of Korea) were seeded at a density of $0.5 \times 10^{3}$ cells per well and the medium used for cell culture was DMEM high glucose media (Biowest, France) supplemented with penicillin-streptomycin solution (Biowest, France), Plasmocin ${ }^{\text {TM }}$ prophylactic (Biowest, France) and fetal bovine serum. Cells were incubated in a $\mathrm{CO}_{2}$ atmosphere at $37^{\circ} \mathrm{C}$ for $24 \mathrm{~h}$ prior to treating with essential oil. The plant essential oils were prepared in four concentrations $10^{-8}, 10^{-6}, 10^{-4}$, and $10^{-2}$. After $24 \mathrm{~h}$, the cells are treated with diluted plant essential oil and incubated for $24 \mathrm{~h}$. Subsequently, after removing the medium with the plant essential oil from cells, the cells are washed with PBS solution (WELGENE, Republic of Korea). EZ-Cytox reagent (DoGenBio, Republic of Korea) was used for evaluating cell viability. The absorbance was measured at $450 \mathrm{~nm}$ with Epoch microplate spectrophotometer (BioTek, USA). Cell viability (\%) was determine by calculating the optical density (OD) by using the formula OD sample / OD control (vehicle) $\times 100$ for each concentration range. A cell survival curve was calculated from these values, and the $\mathrm{IC}_{50}$ value was established. After conducting the CCK assay, the same procedure was repeated with plant essential oils that were diluted to concentrations of $10^{-6}, 10^{-5}, 10^{-4}, 10^{-3}, 10^{-2}$.

\subsection{RNA Extraction}

Cells were seeded in 6-well plates at a density of $0.3 \times 10^{-4}$ cells per well and incubated at $37^{\circ} \mathrm{C}$ in $5 \%$ $\mathrm{CO}_{2}$ atmosphere. Plant essential oils in DMEM high glucose media (Biowest, France) were prepared in three concentrations: $\mathrm{IC}_{50}$ from the $\mathrm{CCK}$ assay, 10 times more than the IC50, and 10 times less than the $\mathrm{IC}_{50}$. When cell confluence was $70 \%$, the cells were treated with the appropriate concentration from preliminary experiment $\left(10^{-5} \sim 10^{-3}\right.$ or $\left.10^{-4} \sim 10^{-2}\right)$ of plant essential oil.
Harvesting of cells and RNA extraction were accomplished by using TRI reagent (Invitrogen, USA) at $24 \mathrm{~h}$ after plant essential oil treatment. The purity and concentration of the extracted RNA were measured by using an Epoch microplate spectrophotometer (BioTek, USA).

\subsection{Synthesis of cDNA}

The extracted RNA was synthesized by reverse transcription. The concentration of RNA was titrated to $1 \mu \mathrm{g} / \mu \mathrm{L}$ and DEPC-treated water was added to adjust the total volume to $10.5 \mu \mathrm{L}$. The mixture contained Moloney murine leukemia virus (MMLV) reverse transcriptase (Invitrogen, USA), Ribonuclease inhibitor (Invitrogen, USA), random primers (6-mers; TaKaRa, Japan), $100 \mathrm{mM}$ DTT (Invitrogen, USA), dNTP, and $5 \times$ first strand buffer. The reaction mixture was incubated at $37^{\circ} \mathrm{C}$ for $60 \mathrm{~min}$. After synthesizing cDNA, the enzyme mixture were incubated at $95^{\circ} \mathrm{C}$ for $5 \mathrm{~min}$ for inactivation. After cooling for $5 \mathrm{~min}$ on ice, the cDNA was stored at $-20^{\circ} \mathrm{C}$ prior to use.

\subsection{Real-time Polymerase Chain Reaction}

For real-time polymerase chain reaction (RT-PCR), a mastermix of the following reaction components was prepared: cDNA sample $(2 \mu \mathrm{L}), 0.25 \mu \mathrm{L} 50 \times$ ROX dye, $6.25 \mu \mathrm{L} 2 \times$ prime Q-mastermix SYBR (GeNetBio, Korea), $0.5 \mu \mathrm{L}$ forward primer, and $0.5 \mu \mathrm{L}$ reverse primer. RT-PCR was performed using 7300 RT-PCR system (Applied Biosystems, Foster City, CA, USA) and the procedure sequence was as follows: cDNA denatured at $95^{\circ} \mathrm{C}$ for $30 \mathrm{sec}$ and annealed at $58^{\circ} \mathrm{C}$ for $30 \mathrm{sec}$, elongation is performed at $72^{\circ} \mathrm{C}$ for $30 \mathrm{sec}$, and the whole cycle is repeated 40 times. The degree of gene expression was determined by using RQ software (Applied Biosystems).

The primer sequences used are as follows: 5'-CATA CTCCACAGCACCTGGTTA-3' (forward) and 5'-CTGT 
TGCCACCTTTCGGTTA-3' (reverse) for caspase-3; 5'-TACTTTCTGCATCAGCAGCC-3' (forward) and 5'-TGATTCAGGCCAGCTTTGTC-3' (reverse) for cyclinA; 5'-CTTTGCACTTCCTTCGGAGA-3' (forward) and GTAGAGTTGGTGTCCATTCACC-3' (reverse) for cyclinB; 5'-CCTCGGTGTCCTACTTCA-3' (forward) and 5'-CTCCTCGCACTTCTGTTC-3' (reverse) for cyclinD; and 5'-GGTTTCAGGGRATCAGTGGT-3' (forward) and 5'-TTTCTTTGCTCGGGGCTTTG-3' (reverse) for cyclinE. The primer sequence for Rn18s was used as the primer for the control group: 5'-CTCAA CACGGGAAACCTCAC-3' (forward) and 5'-CGCTC CACCAACTAAGAACG-3' (reverse). All primers were synthesized from Macrogen (Republic of Korea).

\subsection{Data Analysis}

All data were analyzed by applying nonparametric one-way analysis of variance followed by Tukey's test for multiple comparisons. All experiments consisted of three separate trials. Statistical analysis was performed by using Prism Graph Pad (v.4.0; GraphPad Software, USA).

\section{RESULTS and DISCUSSION}

\subsection{Two-step Identification of $\mathrm{IC}_{50}$ Value of Each Essential Oils}

$\mathrm{IC}_{50}$ values were obtained by performing CCK-8 assays. To determine the test concentration, the cells were treated with four concentrations of CCK-8, followed by further subdivision within the CCK- 8 assay. The $\mathrm{IC}_{50}$ values for the 10 plant essential oils tested are presented in Figs. 1 and 2. In each cell line, cytotoxic degree of each essential oil was classified as low toxicity $\left(\sim 1 \times 10^{-4}\right)$, intermediate toxicity $\left(\sim 1 \times 10^{-5}\right)$, or high toxicity $\left(1 \times 10^{-6} \sim\right)$. The A549 cell line showed

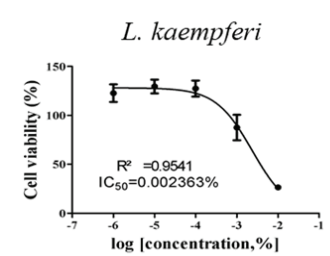

Z. ailanthoides
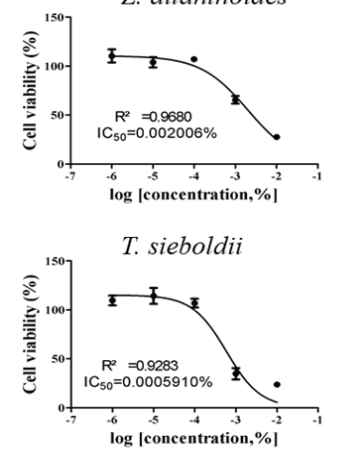
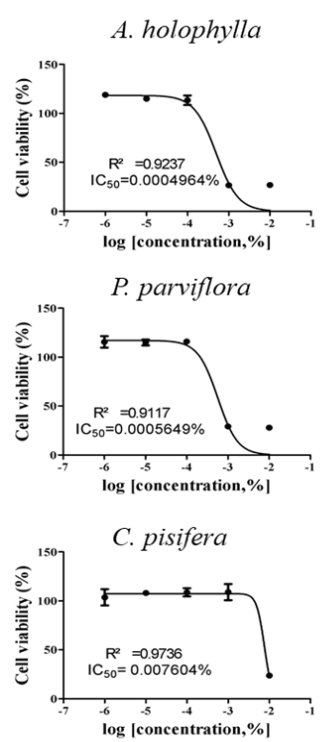

C. japonica

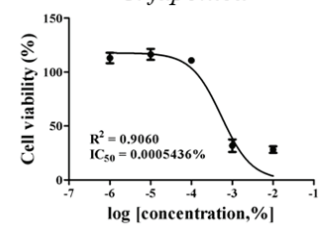

I. anisatum

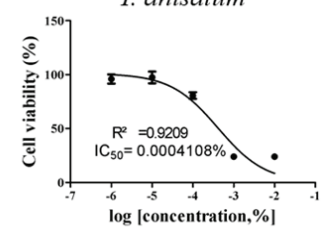

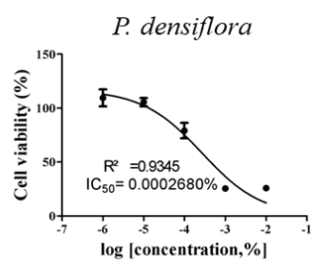

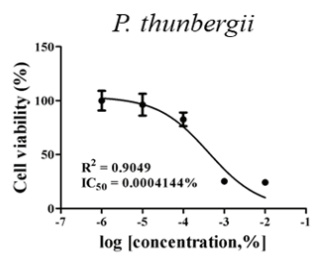

Fig. 1. Cell survival curves for determining the $\mathrm{IC}_{50}$ values of essential oil in the A549 cell line. Through the foregoing experiments conducted to determine the experimental concentration, essential oil was diluted to a more detailed five concentrations; $10^{-6}, 10^{-5}, 10^{-4}, 10^{-3}, 10^{-2}$. After the cells are treated with essential oils, the OD value was measured using the CCK- 8 assay. Cell viability was determined by OD value (sample) / OD value (control) $\times 100(\%)$ and the $\mathrm{IC}_{50}$ value is measured through the drawn survival curve. 
L. kaempferi

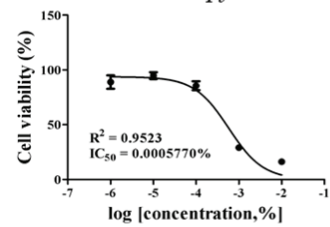

Z. ailanthoides

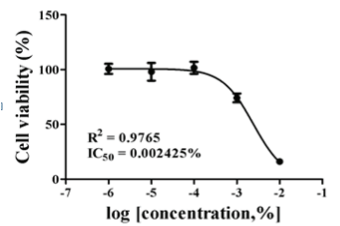

T. sieboldii

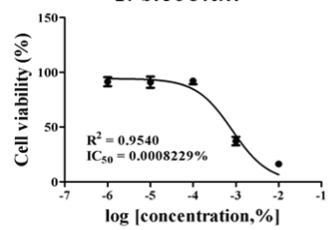

A. holophylla

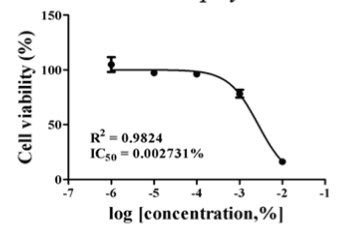

P. parviflora

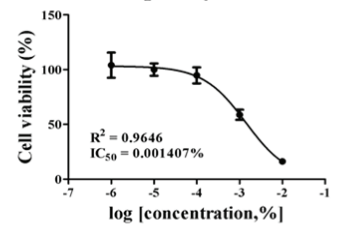

C. pisifera

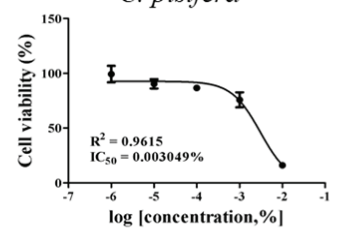

C. japonica

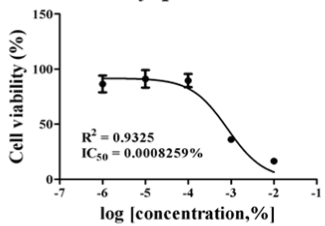

I. anisatum

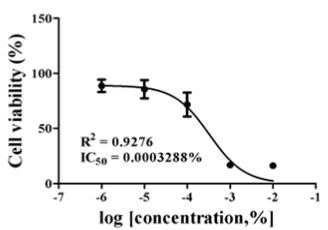

P. densiflora

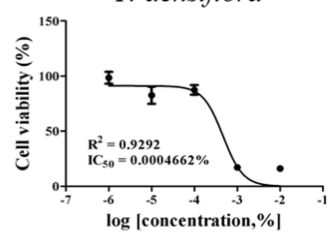

P. thunbergii

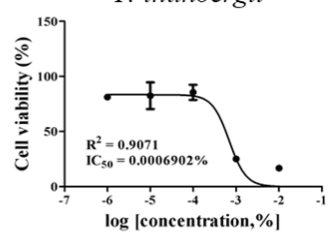

Fig. 2. Cell survival curves for determining the $\mathrm{IC}_{50}$ values of essential oil in the Detroit551 cell line. Through the foregoing experiments conducted to determine the experimental concentration, essential oil was diluted to a more detailed five concentrations; $10^{-6}, 10^{-5}, 10^{-4}, 10^{-3}, 10^{-2}$. After the cells are treated with essential oils, the OD value was measured using the CCK- 8 assay. Cell viability was determined by OD value (sample) / OD value (control) $\times 100(\%)$ and the $\mathrm{IC}_{50}$ value is measured through the drawn survival curve.

low cytotoxicity to L. kaempferi, Z. ailanthoides, and C. pisifera treatment, while A. holophylla, P. parviflora, T. sieboldti, C. japonica, P. densiflora, I. anisatum, and $P$. thunbergii treatments were intermediately toxic to A549 cells. In the Detroit551 cell line, A. holophylla, Z. ailanthoides, P. parviflora, T. sieboldti, and $C$. pisifera produced low cytotoxicity, and L. kaempferi, C. japonica, P. densiflora, I. anisatum, and P. thunbergii were moderately toxic.

\subsection{Expression of Caspase-3 Gene Affected by Plant Essential Oils}

Expression levels of caspase-3 gene after essential oil treatment of A549 and Detroit551 cells, a marker gene related to cell apoptosis, were determined by performing RT-PCR. The expression level of caspase-3 in the A549 and Detroit551 cell line after treatment with plant essential oil is shown in Fig. 3. The expression level of caspase- 3 gene decreased in high concentrations of $Z$. ailanthoides, $C$. japonica, and I. anisatum, while it increased in low concentration $T$. sieboldti. The expression of caspase-3, a cytotoxicity marker, increased at concentrations near the $\mathrm{IC}_{50}$ values of $L$. kaempferi, and Z. ailanthoides in Detroit551 cell line.

\subsection{Expression of CyclinA, CyclinB, CyclinD, and CyclinE Affected by Plant Essential Oils}

The expression levels of cyclinA, cyclinB, cyclinD, and cyclinE in the A549 cell as plant essential oil treatment at different concentrations are shown in Fig. 4. The concentrations of essential oils are determined 
(A)

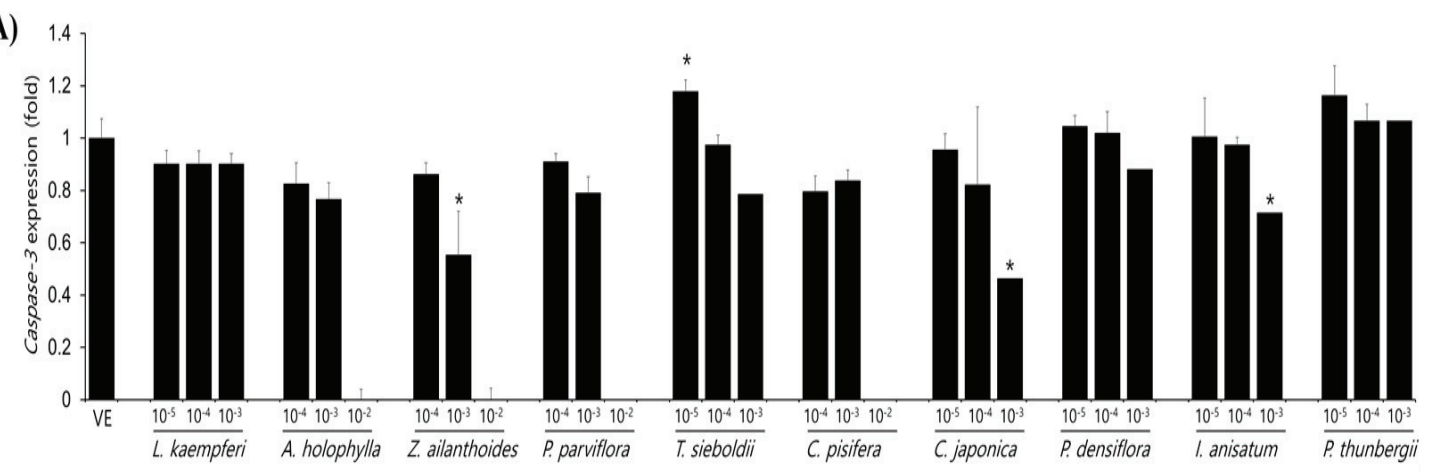

(B)

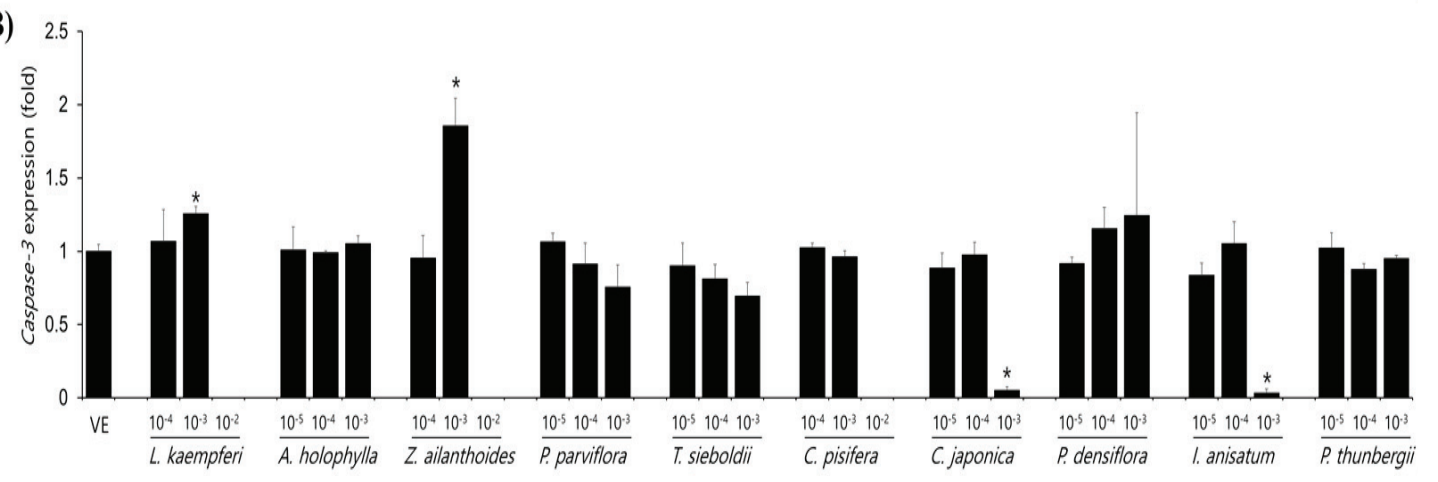

Fig. 3. The expression level of Caspase- 3 in A549 and Detroit551 cells after treatment with essential oil. Relative expression of caspase-3 in A549 cell (A), and Detroid-551 cell (B). Based on the $\mathrm{IC}_{50}$ values obtained above, three concentrations were set so that the difference was 10 times back and forth. The expression levels of Casepase- 3 in each group were determined by real time polymerase chain reaction after treatment with three concentrations of essential oil. ${ }^{*} P<0.05$ vs. vehicle. Data are presented as mean $\pm \mathrm{SD}$ values.

with $\mathrm{IC}_{50}$ value from $\mathrm{CCK}$ assay. The cell-cycle control gene, cyclinA, showed a concentration-dependent decrease in all samples except C. pisifera. CyclinB showed a concentration-dependent decrease in cell-cycle marker protein in all 10 oils tested. In the A549 cell line, cyclinD expression was significantly decreased in $Z$. ailanthoides, C. japonica, and $I$. anisatum oils, while cyclinE expression showed a decrease in all species except $P$. thunbergii. Expression of cyclinE was observed at a concentration approximately 10 times the $\mathrm{IC}_{50}$ value when treated with $P$. thunbergii oil. The expression levels of cyclinA, cyclinB, cyclinD, and cyclinE in the Detroit551 cell line according to plant essential oil concentrations are shown in
Fig. 5. CyclinA, a cell- cycle regulator, showed a concentration-dependent decrease in Detroit551 cells for all species except $C$. pisifera. This tendency was the same as the A549 cells, a lung cell line. CyclinB analysis showed a concentration- dependent decrease in all species except $C$. pisifera. The cyclinD results showed that expression of the cell-cycle marker protein was significantly different among several oils. Extracts of L. kaempferi, Z. ailanthoides, C. japonica, and I. anisatum showed a concentration-dependent decrease, while the other species did not show a decreasing tendency. The expression level of cyclinE showed that there was a significant decline in L. kaempferi, T. sieboldti, C. japonica, and I. anisatum. 


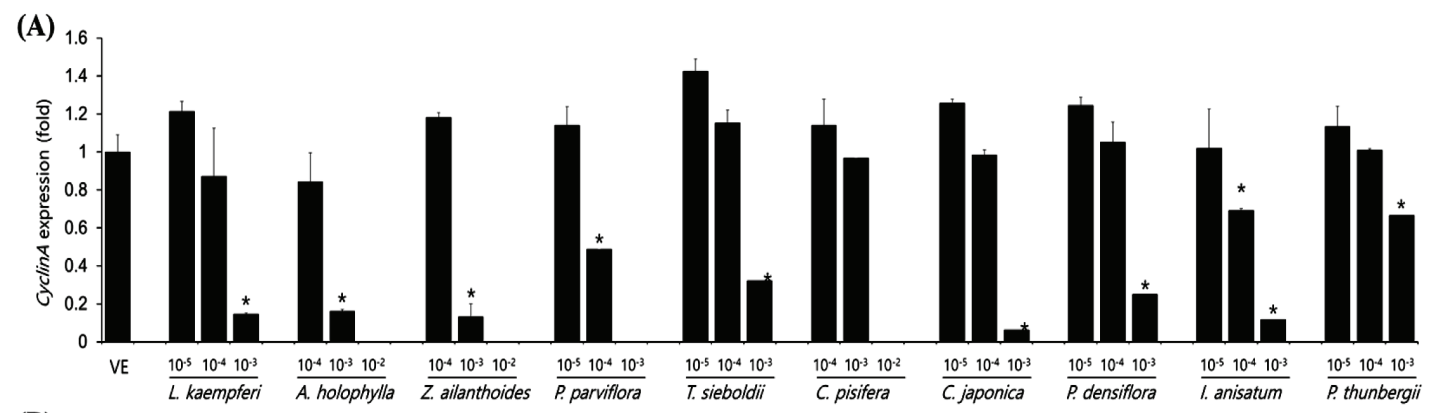

(B)

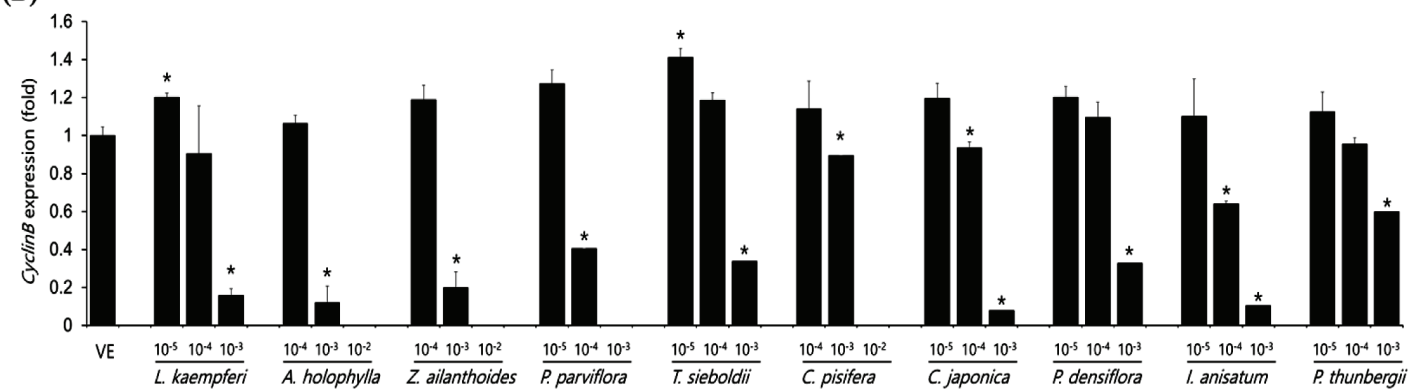

(C)

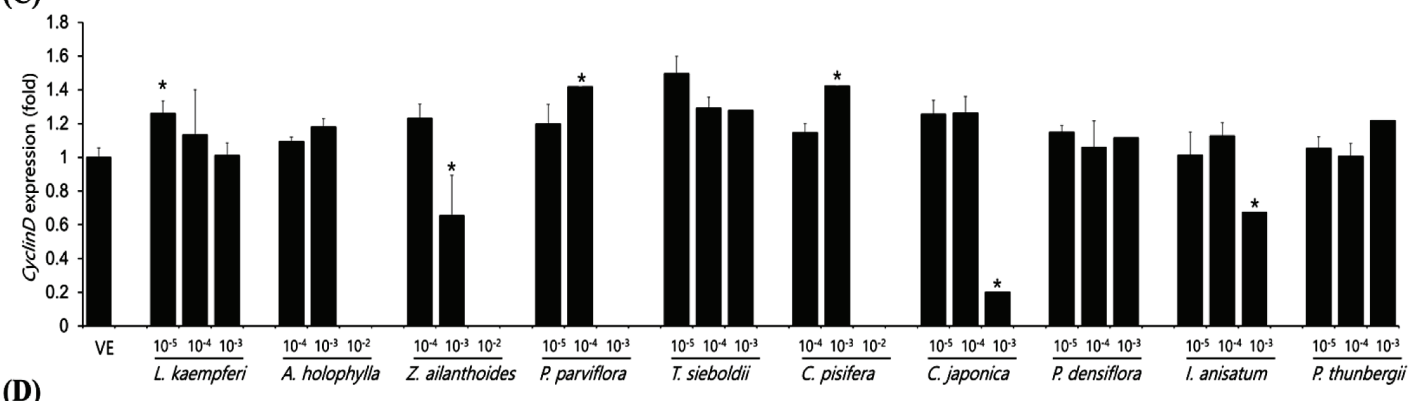

(D)

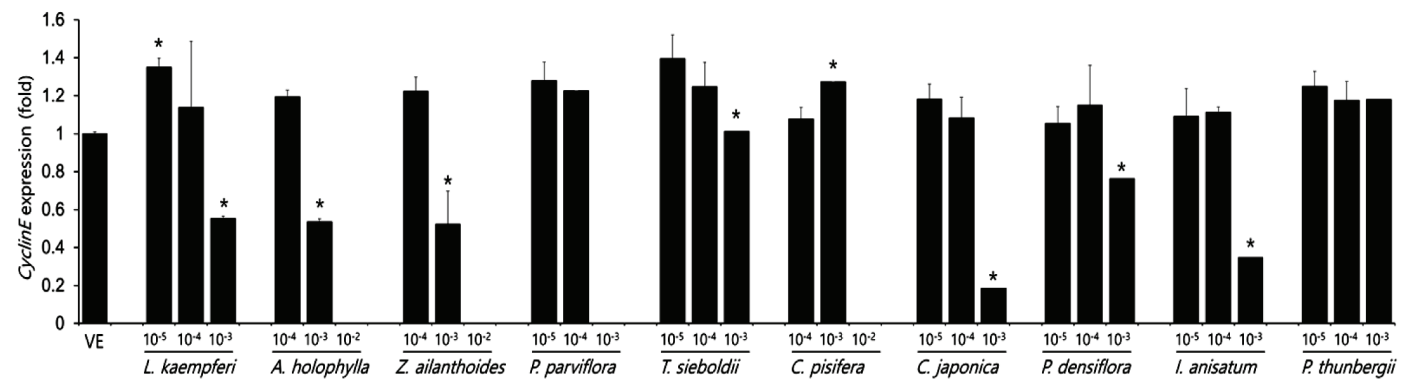

Fig. 4. The expression level of CycllinA, CyclinB, CyclinD, CyclinE in A549 cells after treatment with essential oil. Based on the $\mathrm{IC}_{50}$ values obtained above, three concentrations were set so that the difference was 10 times back and forth. The expression levels of CyclinA (A), CyclinB (B), CyclinD (C), CyclinE (D) in each group were determined by real time polymerase chain reaction after treatment with three concentrations of essential oil. $* P<0.05$ vs. vehicle. Data are presented as mean \pm SD values. 

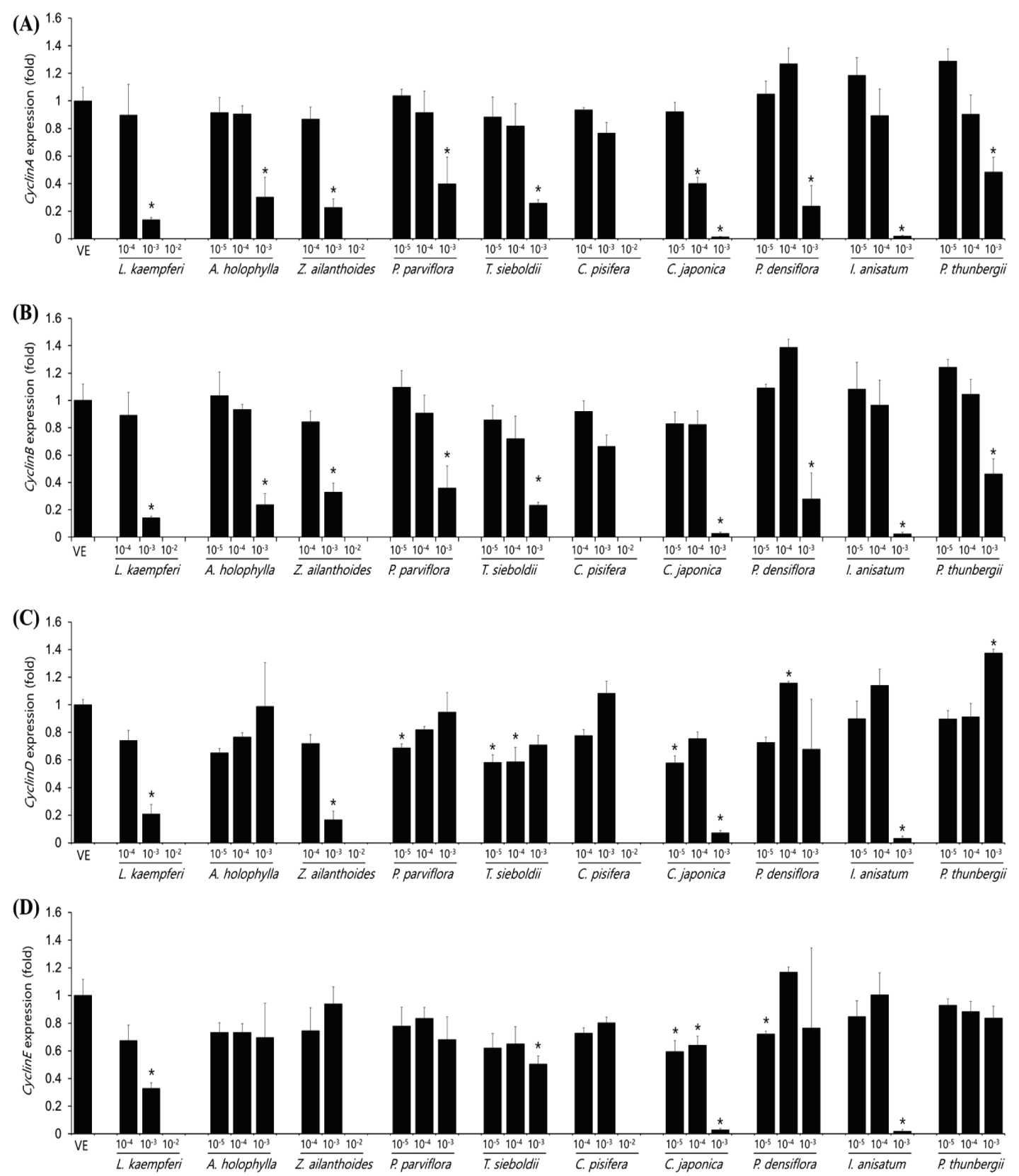

Fig. 5. The expression level of CycllinA, CyclinB, CyclinD, CyclinE in Detroit551 cells after treatment with essential oil. Based on the $\mathrm{IC}_{50}$ values obtained above, three concentrations were set so that the difference was 10 times back and forth. The expression levels CyclinA (A), CyclinB (B), CyclinD (C), CyclinE (D) in each group were determined by real time polymerase chain reaction after treatment with three concentrations of essential oil. ${ }^{*} \mathrm{P}<0.05$ vs. vehicle. Data are presented as mean $\pm \mathrm{SD}$ values. 


\subsection{Discussion}

Essential oils have been used in traditional medicine. Researches in this area is growing by systematic and scientific approaches for the biological activities of phytotherapeutics targets in last few decades. The availabilities of essential oils seem to have a great potential as anti-inflammatory, anti-bacterial, anti-cancer therapeutic agents and aromatherapies (Bravo and Celis, 1980; Pagano et al., 1992; Elledge, 1996; Min et al., 2017). Their complex chemical composition makes it difficult to examine the biological effect, which is likely the show biological activity of each component. However, information regarding their mechanism of action is still lacking and far from being deciphered. Indeed, it was difficult that the mechanism and biological effects of complex chemical compositions in cell toxicity or cytostatic effects (Russo et al., 2015). As though, we tried to understand the effects of plant essential oils by CCK-8 assay and cytotoxicity-related marker gene analyses with two cell line A549 and Detroit551 for evaluation of their cytotoxic and antiproliferative actions. The reason for selection of these cells is the main route of action for essential oil are inhalation and percutaneous route.

The $\mathrm{IC}_{50}$ values determined by the CCK- 8 assay showed low toxicities in the A549 cell line from $L$. kaempferi, Z. ailanthoides, and C. pisifera oils, whereas extracts of $A$. holophylla, P. parviflora, T. sieboldti, C. japonica, $P$. densiflora, I. anisatum, and $P$. thunbergii produced moderate toxicity. In the Detroit551 cell line, A. holophylla, Z. ailanthoides, P. parviflora, T. sieboldti, and $C$. pisifera produced low toxicity, while $L$. kaempferi, C. japonica, P. densiflora, I. anisatum, and $P$. thunbergii produced moderate toxicity. In addition to determining toxicity levels, we examined the expression levels of five marker genes to assess the cell death pathway. Expression of caspase-3 in the A549 cell line decreased under high concentrations of $Z$. ailanthoides, C. japonica, and I. anisatum, whereas $T$. sieboldti oil produced an increase in caspase-3 expression at low concentration. There were no concentrationdependent increases or decreases in the expression of caspase-3 gene in all tested essential oil samples; thus, confirming that the decrease in cell numbers of the lung cell line was not a result of apoptosis (Citron et al., 2000). Subsequently, we evaluate cell cycle regulator genes cyclin, which regulate cell proliferation. The expression level of cyclinA, a cell-cycle marker, in the A549 cell line is shown in Fig. 4. The concentrationdependent expression of cyclinA was decreased in all oil samples except that extracted from $C$. pisifera. This suggests that cytotoxicity through inhibition of cell proliferation occurred in all essential oils except that from C. pisifera. The expression level of cyclinB is shown in Fig. 4, which shows that the expression of cyclinB decreases in a concentration- dependent manner in all species. This suggests that the cytotostatic effect of these oils in lung cell lines is due to inhibition of cell proliferation rather than to apoptosis (Jeong et al., 2009). Unlike cyclins A, B, and E, the expression of cyclinD was markedly decreased when treated with $Z$. ailanthoides, C. japonica, and I. anisatum. Therefore, it is thought that cytotoxicity results at high concentration of those essential oils is due to inhibition of specific phases in the cell cycle (Schmidt et al., 2002). The expression of cyclinE showed a concentrationdependent decrease in all oils except $P$. thunbergii. Decrease of cyclinE expressions were observed at a concentration approximately 10 times the $\mathrm{IC}_{50}$ values of Larix kaempferi, Tsuga sieboldt, Cryptomeria japonica, Pinus densiflora and Illicium anisatum. These results suggest that different types of essential oils affect different phases of the cell proliferation.

The expression level of caspase- 3 in the Detroit551 cell line increased at concentrations near the $\mathrm{IC}_{50}$ values for L. kaempferi, and Z. ailanthoides. Therefore, when essential oil extracts of $L$. kaempferi and $Z$. ailanthoides 
at a high concentration are treated to Detroit551 cells, the decrease in cell numbers would be the result of apoptosis (Namura et al., 1998). These results are opposite to the result with A549 cell line. In previous researches, cytotoxic effect due to apoptosis could be shown depends on cell type (Russo et al., 2015). Expression of cyclinA in the Detroit551 cell line decreased following treatment by all oils except that of C. pisifera; a similar trend was observed in the A549 cell line. CyclinB expression in the Detroit551 cell line showed a concentration-dependent decrease after treatment by all oils except $C$. pisifera oil. Cytotoxicity of the essential oils of these species in skin cell lines is due to inhibition of cell proliferation rather than due to apoptosis (Goldwasser et al., 1996). The results of the cyclinD analysis showed the greatest differences among the tested species; L. kaempferi, Z. ailanthoides, C. japonica, and I. anisatum showed a concentrationdependent decrease, while the other species did not show a decreasing tendency. Finally, analysis of cyclinE showed that there were significant decreasing trends following treatment with L. kaempferi, T. sieboldti, C. japonica, and I. anisatum oils.

In conclusion, cell growth is induced by cyclinD which is required for all cell cycle stage, cyclinE for G1/S transition, cyclinA for G2 phase, cyclin B for Mitosis. Phosphorylation of pRB proteins by the cyclindependent kinases (CDKs) releases E2F factors, promoting the transition to next cycle (Duronio and Xiong 2013). Regulation of cyclin could be used for cancer treatment with carefully chosen dosage. But in ahead of usage, cytotoxic evaluation (identifying $\mathrm{IC}_{50}$ ). Expressions of all marker genes in the A549 cell line after treatment with the plant essential oils of $Z$. ailanthoides, $C$. japonica, and I. anisatum were down-regulated. After L. kaempferi, A. holophylla, P. parviflora, and T. sieboldti treatment, only cyclinA, cyclinB, and cyclinE were downregulated. Down-regulation of cyclinB and cyclinE was observed in C. pisifera treatment, and down-regulation of cylinA and cyclinB was observed in P. thunbergii treatment. In the Detroit551 cell line, changes in expression level of caspase-3 were observed in two species' essential oils: L. kaempferi, and Z. ailanthoides. CyclinA, cyclinB, cylinD, and cylinE gene markers were all down-regulated by L. kaempferi essential oil treatment, whereas caspase-3 genes were down-regulated in three genes, cyclinA, cyclinB, and cyclinD. Essential oils of A. holophylla, P. parviflora, P. densiflora, P. thunbergii affected only two genes, cyclinA and cyclinB, which were down-regulated. CyclinA, cyclinB, and cyclinE were down-regulated by $T$. sieboldti, and all five marker genes were down-regulated by $C$. japonica and $I$. anisatum essential oils.

\section{CONCLUSION}

With those results, in turn, essential oils can regulate depends on its own chemical contents and concentration, the right selection of kind and concentration of essential oils are important for the source of medicine and cosmetic usage.

\section{ACKNOWLEDGMENT}

This work was financially supported by 'Forest Science Technology Program (Project No. '(FP0900-2016-01)' provided by National Institute of Forest Science and the Research Year of Chungbuk National University in 2017.

\section{REFERENCES}

Bravo, R., Celis, J.E. 1980. A search for differential polypeptide synthesis throughout the cell cycle of HeLa cells. The Journal of Cell Biology 84(3): 795-802.

Citron, B.A., Arnold, P.M., Sebastian, C., Qin, F., Malladi, S., Ameenuddin, S., Landis, M.E., Festoff, 
B.W. 2000. Rapid upregulation of caspase-3 in rat spinal cord after injury: mRNA, protein, and cellular localization correlates with apoptotic cell death. Experimental Neurology 166(2): 213-226.

Duronio, R.J., Xiong, Y. 2013. Signaling pathways that control cell proliferation. Cold Spring Harbor Perspectives in Biology 5(3): a008904.

Elledge, S.J. 1996. Cell cycle checkpoints: preventing an identity crisis. Science 274(5293): 1664-1672.

Galindo, L.A., Pultrini Ade, M., Costa, M. 2010. Biological effects of Ocimum gratissimum L. are due to synergic action among multiple compounds present in essential oil. Jounal of Nature Medicine 64(4): 436-441.

Goldwasser, F., Shimizu, T., Jackman, J., Hoki, Y., O'Connor, P.M., Kohn, K.W., Pommier, Y. 1996. Correlations between $\mathrm{S}$ and $\mathrm{G} 2$ arrest and the cytotoxicity of camptothecin in human colon carcinoma cells. Cancer Research 56(19): 44304437.

Grana, X., Reddy, E.P. 1995. Cell cycle control in mammalian cells: role of cyclins, cyclin dependent kinases (CDKs), growth suppressor genes and cyclin-dependent kinase inhibitors (CKIs). Oncogene 11(2): 211-219.

Ha, M.W., Ma, R., Shun, L.P., Gong, Y.H., Yuan, Y. 2005. Effects of allitridi on cell cycle arrest of human gastric cancer cells. World Journal of gastroenderology 11(35): 5433-5437.

Jeong, J.H., An, J.Y., Kwon, Y.T., Rhee, J.G., Lee, Y.J. 2009. Effects of low dose quercetin: cancer cell-specific inhibition of cell cycle progression. Journal of Cellular Biochemistry 106(1): 73-82.

Kahkonen, M.P., Hopia, A.I., Vuorela, H.J., Rauha, J.P., Pihlaja, K., Kujala, T.S., Heinonen, M. 1999. Antioxidant activity of plant extracts containing phenolic compounds. Journal of Agricultural and Food Chemistry 47(10): 3954-3962.

Lambert, R.J., Skandamis , P.N., Coote, P.J., Nychas,
G.J. 2001. A study of the minimum inhibitory concentration and mode of action of oregano essential oil, thymol and carvacrol. Journal of Applied Microbiology 91(3): 453-462.

Lee, H.R., Kim, G.H., Choi, W.S., Park, I.K. 2017. Repellent Activity of Apiaceae Plant Essential Oils and their Constituents Against Adult German Cockroaches. Journal of Econimic Entomology 110(2): 552-557.

Lee, S.Y., Kim, S.H., Park, M.J., Lee, S.S., Choi, I.G. 2014. Antibacterial Activity of Essential Oil from Abies holophylla against Respiratory Tract Bacteria. Journal of the Korean Wood Science and Technology 42(5): 533-542.

Min, H.J., Kim, C.S., Hyun, H.J., Bae, Y.S. 2017. Essential Oil Analysis of Illicium anistum L. Extracts. Journal of the Korean Wood Science and Technology 45(6): 682-688.

Muschel, R.J., Zhang, H.B., Iliakis, G., McKenna, W.G. 1991. Cyclin B expression in HeLa cells during the G2 block induced by ionizing radiation. Cancer Research 51(19): 5113-5117.

Namura, S., Zhu, J., Fink, K., Endres, M., Srinivasan, A., Tomaselli, K.J., Yuan, J., Moskowitz, M.A. 1998. Activation and cleavage of caspase-3 in apoptosis induced by experimental cerebral ischemia. Journal of Neuroscience 18(10): 3659-3668.

Ohtsubo, M., Theodoras, A.M., Schumacher, J., Roberts, J.M., Pagano, M. 1995. Human cyclin E, a nuclear protein essential for the G1-to-S phase transition. Molecular and Cellular Biology 15(5): 2612-2624.

Pagano, M., Pepperkok, R., Verde, F., Ansorge, W., Draetta, G. 1992. Cyclin A is required at two points in the human cell cycle. EMBO Journal 11(3): 961-971.

Porter, A.G., Janicke, R.U. 1999. Emerging roles of caspase-3 in apoptosis. Cell Death \& Differentiation 6(2): 99-104.

Prabuseenivasan, S., Jayakumar, M., Ignacimuthu, S. 
2006. In vitro antibacterial activity of some plant essential oils. BMC Complementary and Alternative Medicine 6: 39.

Russo, R., Corasaniti, M.T., Bagetta, G., Morrone, L.A. 2015. Exploitation of cytotoxicity of some essential oils for translation in cancer therapy. EvidenceBased Complementary and Alternative Medicine 2015: 397821.

Schmidt, M., Fernandez de Mattos, S., van der Horst, A., Klompmaker, R., Kops, G.J., Lam, E.W., Burgering, B.M., Medema, R.H. 2002. Cell cycle inhibition by FoxO forkhead transcription factors involves downregulation of cyclin D. Mollecualr and Cellular Biolology 22(22): 7842-7852.

Sherr, C.J. 1994. G1 phase progression: cycling on cue. Cell 79(4): 551-555.

Sienkiewicz, M., Glowacka, A., Kowalczyk, E., Wiktorowska-Owczarek, A., Jozwiak-Bebenista,
M., Lysakowska, M. 2014. The biological activities of cinnamon, geranium and lavender essential oils. Molecules 19(12): 20929-20940.

Wang, Y., Baskerville, S., Shenoy, A., Babiarz, J.E., Baehner, L., Blelloch, R. 2008. Embryonic stem cell-specific microRNAs regulate the G1-S transition and promote rapid proliferation. Nature Genetics 40(12): 1478-1483.

Waseem, R., Low, K.H. 2015. Advanced analytical techniques for the extraction and characterization of plant-derived essential oils by gas chromatography with mass spectrometry. Journal of Separation Science 38(3): 483-501.

Zhang, Q., Wu, X., Liu, Z. 2016. Primary Screening of Plant Essential Oils as Insecticides, Fumigants, and Repellents Against the Health Pest Paederus fuscipes (Coleoptera: Staphylinidae). Journal of Econimic Entomology 109(6): 2388-2396. 